\title{
Experimental Investigation of Tensile Strength of Fiber Reinforced Polyester by Using Chicken Feather Fiber
}

\author{
M. Loganathan ${ }^{1, *}$, S. Dinesh ${ }^{2}$, V. Vijayan ${ }^{2}$, M. Ranjithkumar ${ }^{2}$ and S. Rajkumar ${ }^{3}$ \\ ${ }^{1}$ Department of Mechanical Engineering, M. Kumarasamy College of Engineering, Karur, Tamilnadu 639113, India \\ ${ }^{2}$ Department of Mechanical Engineering, K. Ramakrishnan College of Technology, Tiruchirappalli, Tamilnadu 621112, India \\ ${ }^{3}$ Department of Mechanical Engineering, Hawassa Institute of Technology, Hawassa, Ethiopia
}

\section{Corresponding Author Email: logukrr@gmail.com}

\begin{abstract}
In this experimental study essentially focused to the tensile and yield strength of composites of different percentage of Pure Jute fiber with Chicken feather fiber. The major participation of these compositions is pure Jute and minor variations created by the Chicken feather fiber on the basis of weight. There are two variations created for the investigation one is based on four different (A, B, C \& D) percentage variation of fiber used and on that each percentage of Chicken feather fiber variations based on five different length of fiber $(2 \mathrm{~mm}, 4 \mathrm{~mm}, 6 \mathrm{~mm}, 8 \mathrm{~mm} \&$ $10 \mathrm{~mm}$ ) used for the composites. For these different conditions of composite produced and tensile and yield strength measured from testing and compared.
\end{abstract}

Keywords: chicken feather fiber, pure jute, fiber composite, tensile strength, yield strength Received: November-29-2019, Accepted: January-15-2020, https://doi.org/10.14447/jnmes.v23i1.a08

\section{INTRODUCTION}

Composite material growth has been of enormous concentration to researchers and material engineers ever since man revealed that conventional materials could be combined to obtain specific desirable properties hitherto unobtainable [1]. The speed of technological development in the 21 st century has led to a constant demand for innovative composite materials which can meet the unique material property requirements of this new age [2]. Composite materials are at the present broadly used in growing number of commercially significant engineering applications, such as in IC engines, components of machine, thermal power stations, packaging of electronic, automobile, train and aircraft structures and mechanical components, such as brakes, drive shafts, flywheels, tanks, and pressure vessels, piping, automobile springs, offshore structures [3].

The common wastes such as egg shell powders can be added to improve the mechanical properties of the composites [4-6]. When the egg shell powders are added to the fiber, the tensile strength of the developed composite was improved by $18 \%$ and the compressive strength has also increased by $30 \%$. The powder mixed to form the fiber reinforced composite is 100 $\mu \mathrm{m}$ at $10 \%$ of weight of composite [7-10]. Delamination and void formation was identified beyond $10 \%$ of reinforcement in composites. The orientation of the fibers can be varied from $0^{0}$ to $90^{0}$ in order to improve the mechanical properties of composites. Carbon reinforced composites recorded a increase in tensile strength along with appropriate fiber orientation [8]. FEM analysis was used for simulation of mechanical behavior of the composites and was compared with the experimental values in order to create models for predicting the mechanical behavior of new composites [9]. Hybrid epoxy composites mixed with chicken fiber and rubber in appropriate composition has improved the flexural strength, tensile strength and the compression strength of the material when compared to the base materials [10-15]. The composites reinforced with chicken fiber barbs had improved tensile strength than the composite made with chicken fiber rachis. The flexural strength was also high for chicken fiber reinforced composites [16-19]. The fiber length has also had great impact in improvement of the mechanical properties of the composited. Taguchi's technique can be used for identifying the best combination of the reinforcement material and its orientation angle for better mechanical properties [2022]. Glass reinforced composites posted higher impact strength and mechanical characteristics under tension and compression. The elongation characteristics can also be improved by proper reinforcement material and parameters.

\section{EXPERIMENTAL PROCEDURE}

Pure jute fiber and Chicken feather fiber mixed composite created by hand layup method with three different percentage set through epoxy resin. Set A contains $95 \%$ of pure jute fiber and 5\% Chicken feather fiber also there are five different length of chicken feather fiber such as $2 \mathrm{~mm}, 4 \mathrm{~mm}, 6 \mathrm{~mm}, 8 \mathrm{~mm}$ $\& 10 \mathrm{~mm}$ contributed in the same percentage level of composite. For percentage set A contains 5 specimens (A1, A2, A3, A4 \& A5). Similarly Percentage set B contains $90 \%$ of pure jute fiber and $10 \%$ Chicken feather (B1, B2, B3, B4 \& B5), Percentage set $\mathrm{C}$ have $85 \%$ of pure jute fiber and $15 \%$ Chicken feather (C1, C2, C3,C4 \& C5) and Percentage set D have $80 \%$ of pure jute fiber and $20 \%$ Chicken feather (D1, D2, D3, D4 \& D5). The clear details and individual name of the specimen were clearly mentioned in the table 1 . All the specimens were prepared as per the standards of the tensile and yield strength testing requirement in the ultimate tensile machine with 5 ton capacity connected with sensors connected 
setup to the computer for the accurate measurements. Each specimen tested to measure the tensile strength and yield strength. The experimental results were created as a graphical representation for the investigation.

Table 1. Complete detail of specimen compositions for the investigation

\begin{tabular}{|c|c|c|c|c|}
\hline Batch & $\begin{array}{l}\text { Percentage of } \\
\text { Pure Jute }\end{array}$ & $\begin{array}{c}\text { Percentage of } \\
\text { Chicken Feather Fiber }\end{array}$ & $\begin{array}{c}\text { Fiber Length } \\
\text { In Mm } \\
\end{array}$ & $\begin{array}{l}\text { Specimen } \\
\text { Name }\end{array}$ \\
\hline \multirow{5}{*}{ A } & \multirow{5}{*}{$95 \%$} & \multirow[t]{5}{*}{ 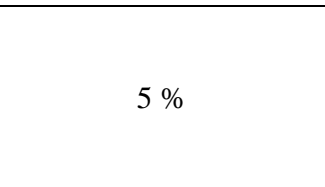 } & 2 & A1 \\
\hline & & & 4 & $\mathrm{~A} 2$ \\
\hline & & & 6 & A3 \\
\hline & & & 8 & A4 \\
\hline & & & 10 & A5 \\
\hline \multirow{5}{*}{ B } & \multirow{5}{*}{$90 \%$} & \multirow{5}{*}{$10 \%$} & 2 & B1 \\
\hline & & & 4 & B2 \\
\hline & & & 6 & B3 \\
\hline & & & 8 & B4 \\
\hline & & & 10 & B5 \\
\hline \multirow{5}{*}{$\mathrm{C}$} & \multirow{5}{*}{$85 \%$} & \multirow{5}{*}{$15 \%$} & 2 & C1 \\
\hline & & & 4 & $\mathrm{C} 2$ \\
\hline & & & 6 & $\mathrm{C} 3$ \\
\hline & & & 8 & $\mathrm{C} 4$ \\
\hline & & & 10 & C5 \\
\hline \multirow{5}{*}{$\mathrm{D}$} & \multirow{5}{*}{$80 \%$} & \multirow{5}{*}{$20 \%$} & 2 & D1 \\
\hline & & & 4 & D2 \\
\hline & & & 6 & D3 \\
\hline & & & 8 & D4 \\
\hline & & & 10 & D5 \\
\hline
\end{tabular}

\section{RESULTS AND DISCUSSION}

Table 2 and Figure 1(a) elaborates the yield strength and tensile strength of the composites that was made with $95 \%$ of pure Jute and $5 \%$ of the fiber. The length of the chicken fiber was varied from $2 \mathrm{~mm}$ to $10 \mathrm{~mm}$ and the stresses were recorded for 5 samples. The yield stress has increased linearly with the increase in length of chicken fiber. It has proved that longer the length of the fiber, the yield stress increases. As such, the tensile strength of the developed composites also increased with the increase in fiber length. It is noted that, the tensile stress decreased for sample 5 which had the chicken fiber length of $10 \mathrm{~mm}$. The maximum tensile stress was recorded with sample 4 which had $95 \%$ of jute fiber and $5 \%$ of chicken fiber with length $8 \mathrm{~mm}$.

Table 2. Stress behavior of Set A Composites

\begin{tabular}{cccc}
\hline $\begin{array}{c}\text { Fiber length } \\
\text { in } \mathbf{~ m m}\end{array}$ & $\begin{array}{c}\text { Specimen } \\
\text { name }\end{array}$ & $\begin{array}{c}\text { Yield strength } \\
\text { (MPa) }\end{array}$ & $\begin{array}{c}\text { Tensile } \\
\text { strength (MPa) }\end{array}$ \\
\hline 2 & A1 & 6.7 & 12 \\
4 & A2 & 8.7 & 13.9 \\
6 & A3 & 10.25 & 16.25 \\
8 & A $~$ & 11.5 & 17.9 \\
10 & A5 & 12.8 & 15.8 \\
\hline
\end{tabular}

Table 3 and Figure 1 (b) represent the stresses generated upon application of load on the composites made of Jute fiber and chicken fibers of varying lengths. It is evident that the average yield and tensile stress of the composites has reduced with the increase in chicken fiber.

It can be seen that there is an increase in yield stress with the increase in fiber length utilized for making the composite upto $6 \mathrm{~mm}$ and the remains constant till 8mm fiber length. A sudden increase is observed when the fiber length is further increased. With regard to tensile strength, an increase is observed in linear form up to $4 \mathrm{~mm}$ fiber length and increases exponentially beyond that.
Table 4 and Figure 1 (c) shows the tensile behavior of composite made with $85 \%$ jute fiber and $15 \%$ of chicken fiber. The stresses induced in the composites have decreased with the increase in chicken fiber fraction. Also, it is noted that with the increase in the fiber length has increased the stress of yielding and tensile. The stress tends to be increasing linearly up to $4 \mathrm{~mm}$ fiber length and remains constant for the composites with the chicken fiber length of $6 \mathrm{~mm}$. Beyond 6 $\mathrm{mm}$ and till $10 \mathrm{~mm}$ fiber length, the stresses tends to increase.

Table 3. Stress behavior of Set B Composites

\begin{tabular}{cccc}
\hline $\begin{array}{c}\text { Fiber length } \\
\text { in } \mathbf{~ m m}\end{array}$ & $\begin{array}{c}\text { Specimen } \\
\text { name }\end{array}$ & $\begin{array}{c}\text { Yield strength } \\
(\mathbf{M P a})\end{array}$ & $\begin{array}{c}\text { Tensile } \\
\text { strength } \mathbf{( M P a})\end{array}$ \\
\hline 2 & B1 & 5.8 & 8.9 \\
4 & B2 & 7.4 & 11.3 \\
6 & B3 & 8.2 & 12.45 \\
8 & B4 & 8.4 & 14.1 \\
10 & B5 & 10.3 & 15 \\
\hline
\end{tabular}

Table 4. Stress behavior of Set C Composites

\begin{tabular}{cccc}
\hline $\begin{array}{c}\text { Fiber length } \\
\text { in } \mathbf{~ m m}\end{array}$ & $\begin{array}{c}\text { Specimen } \\
\text { name }\end{array}$ & $\begin{array}{c}\text { Yield strength } \\
\text { (MPa) }\end{array}$ & $\begin{array}{c}\text { Tensile } \\
\text { strength (MPa) }\end{array}$ \\
\hline 2 & $\mathrm{C} 1$ & 3.6 & 5.8 \\
4 & $\mathrm{C} 2$ & 6.1 & 8.7 \\
6 & $\mathrm{C} 3$ & 6.45 & 8.65 \\
8 & $\mathrm{C} 4$ & 7.7 & 10.3 \\
10 & $\mathrm{C} 5$ & 12 & 14.2 \\
\hline
\end{tabular}

Table 5. Stress behavior of Set D Composites

\begin{tabular}{cccc}
\hline $\begin{array}{c}\text { Fiber length } \\
\text { in mm }\end{array}$ & $\begin{array}{c}\text { Specimen } \\
\text { name }\end{array}$ & $\begin{array}{c}\text { Yield strength } \\
\text { (MPa) }\end{array}$ & $\begin{array}{c}\text { Tensile } \\
\text { strength (MPa) }\end{array}$ \\
\hline 2 & D1 & 1.5 & 3.7 \\
4 & D2 & 3.5 & 6.1 \\
6 & D3 & 2.65 & 4.85 \\
8 & D4 & 3.9 & 6.5 \\
10 & D5 & 11.2 & 13.4 \\
\hline
\end{tabular}


The maximum yield strength and tensile stress was obtained with the composite having the maximum fiber length. This is due to the variation in load distribution on the developed composites.

In this composite, the yielding capacity and the tensile behavior were very much similar for different fiber length. As in set 3 , the behavior of the composite with $80 \%$ Jute fiber and $20 \%$ chicken fiber was similar in nature with regard to tensile and yield stress. The maximum stresses were recorded for the composite with maximum fiber length. But in set 4 , the stresses increased with increase in fiber length upto $4 \mathrm{~mm}$. Further, the stress levels reduced for the composite with $6 \mathrm{~mm}$ fiber length and starts increasing beyond that. This may be due uneven distribution of chicken fiber over the composite. Figure 1 (d) and table 5 has recorded the stresses for various fiber lengths. It is evident from Figure 2 that, the tensile stress of developed composites reduces with the increase in chicken fiber content. Set 1 defines shows the tensile strength of the composites with $2 \mathrm{~mm}$ fiber length for all compositions. Similarly, the tensile behavior of the composites for all other sets also similar. The maximum average tensile strength was recorded for $10 \mathrm{~mm}$ chicken fiber length added composites. Figure 3 shows that, the yielding stress of developed composites reduces with the increase in chicken fiber content for up to chicken fiber length of $8 \mathrm{~mm}$.

The yield stress behavior of composite with $10 \mathrm{~mm}$ fiber length predominantly decreases up to $10 \%$ of chicken fiber addition. But, the yielding capacity of the composite with $15 \%$ addition has increased in comparison with $10 \%$ added composite and again reduces thereafter with the increase in chicken fiber fraction. Again, the average yielding stress is maximum for the composite with $10 \mathrm{~mm}$ fiber length. In each and every plot produce the variations of the corresponding values of the experimental results of the testing in different composition condition. For set A maximum the tensile and the yield strength reached for $8 \mathrm{~mm}$ length of fiber used, similarly set $\mathrm{B}$, set $\mathrm{C}$ and set $\mathrm{D}$ reached the maximum tensile and the yield strength obtained for the fiber with $10 \mathrm{~mm}$ length. But depended upon the percentage of fiber used preposition the maximum tensile and yield strength obtained for the $90 \%$ of pure Jute fiber with $10 \%$ of Chicken feather fiber used composites.

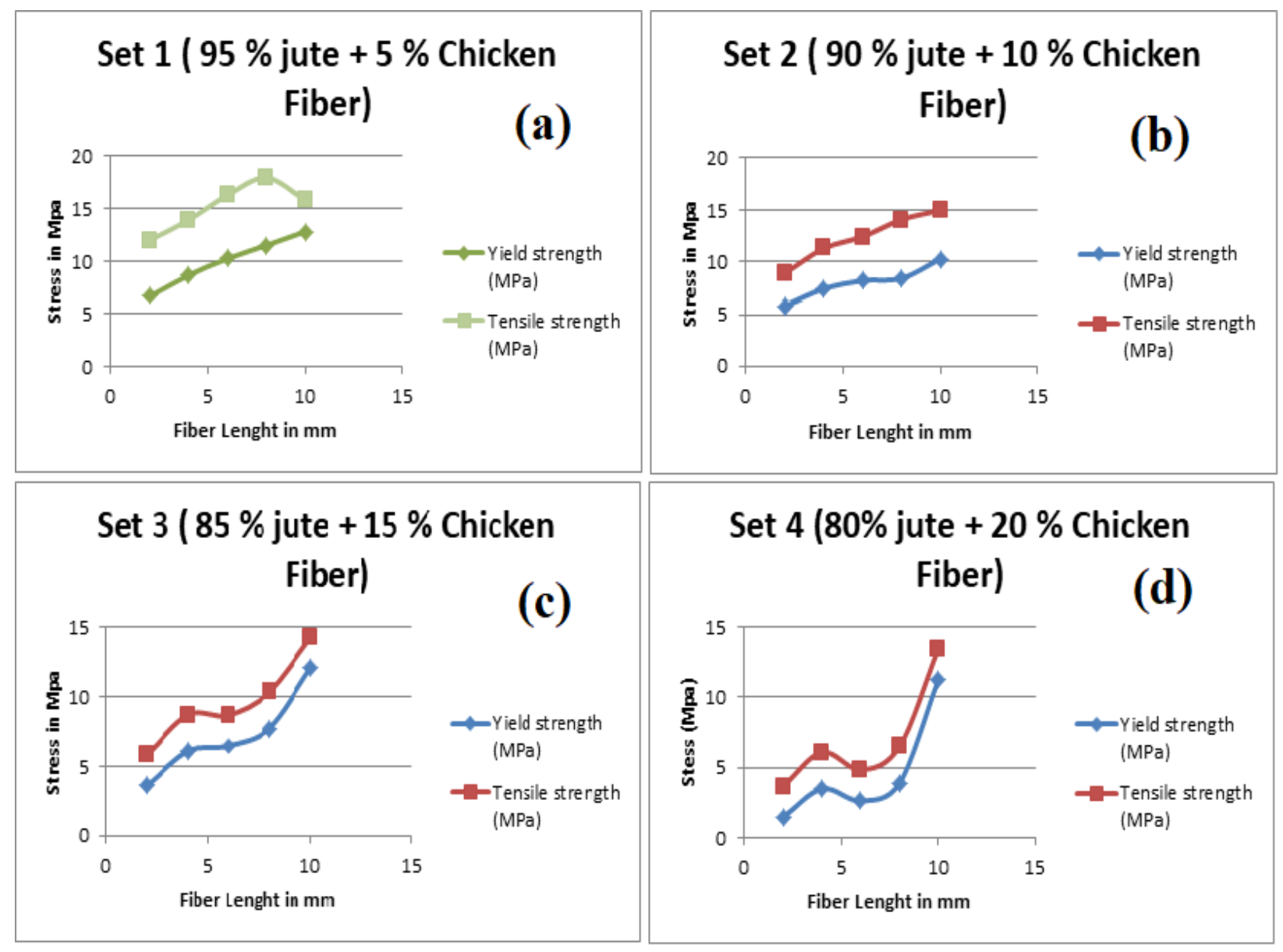

Figure 1. Tensile strength and Yielding capacity of developed composites with varying chicken fiber length 


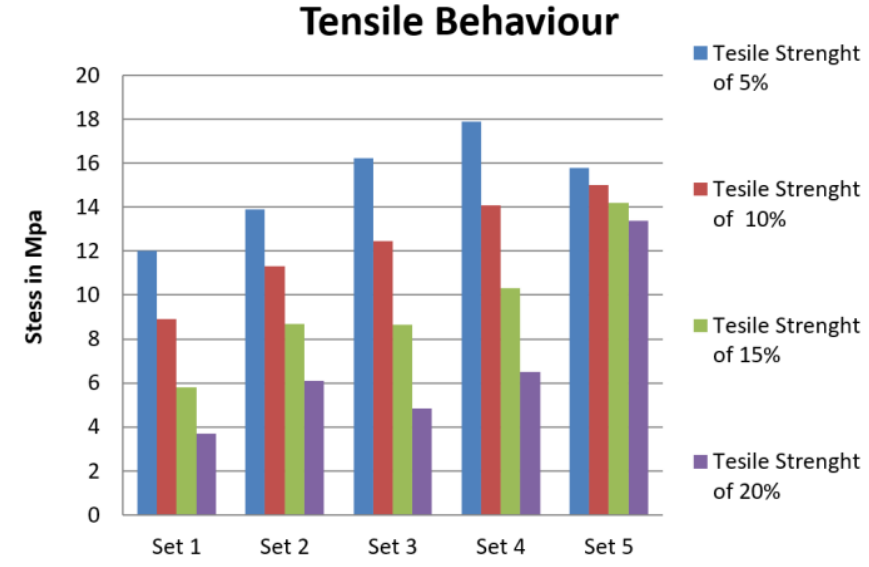

Figure 2. Tensile Behaviour

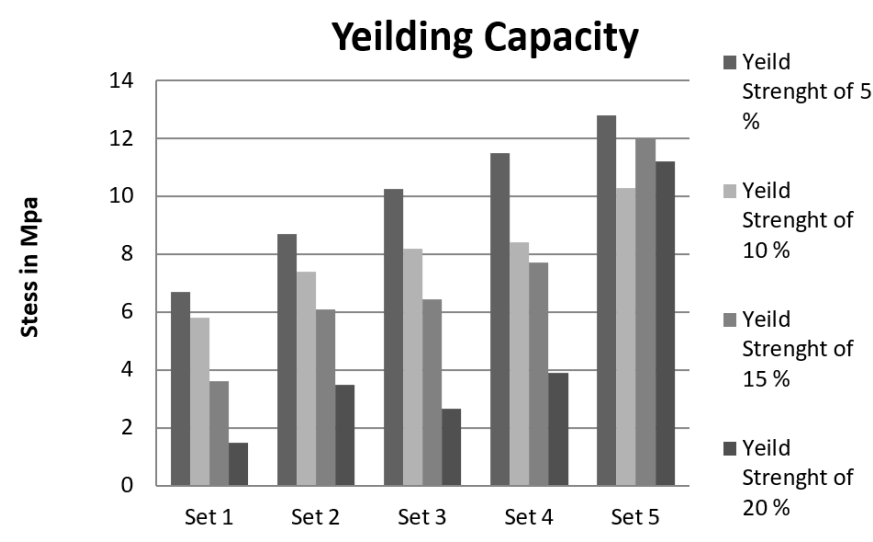

Figure 3. Yielding Capacity

\section{CONCLUSION}

From this experimental study of the tensile and the yield strength analysis on composites of pure jute fiber with Chicken feather fiber, the following conclusions are given:

(1) Percentage variations of Chicken feather fiber produce considerable impact on the tensile strength as well as the yield strength.

(2) In Set A compositions meet the maximum tensile and yield strength for $8 \mathrm{~mm}$ length of chicken feather fiber used in jute fiber.

(3) Chicken feather fiber with length of $10 \mathrm{~mm}$ produce the upper most tensile strength and yield strength for the set B, set $\mathrm{C}$ and set $\mathrm{D}$ when compared to other lengths.

(4) Among these four set of percentage variation composites greatest tensile strength reached for Set A which contains $95 \%$ of pure Jute fiber and $5 \%$ of Chicken feather fiber.

(5) Between these four set of percentage dissimilarity composites, Set A which contains $95 \%$ of pure Jute fiber and $5 \%$ of Chicken feather fiber accomplished the furthermost yield strength.

\section{REFERENCES}

[1] Shin, L.J., Barathi Dassan, E.G., Zainol Abidin, M.S., Anjang, A. (2020). Tensile and compressive properties of glass fiber-reinforced polymer hybrid composite with eggshell powder. Arabian Journal for Science and
Engineering,

45:

5783-5791.

https://doi.org/10.1007/s13369-020-04561-z

[2] Egala, R., Jagadeesh, G.V., Setti, S.G. (2020). Experimental investigation and prediction of tribological behavior of unidirectional short castor oil fiber reinforced epoxy composites. Friction, 1-23. https://doi.org/10.1007/s40544-019-0332-0

[3] Sathish, T., Karthick, S. (2020). Wear behaviour analysis on aluminium alloy 7050 with reinforced $\mathrm{SiC}$ through taguchi approach. Journal of Materials Research and Technology, $\quad 9(3)$ : 3481-3487. https://doi.org/10.1016/j.jmrt.2020.01.085

[4] Sathish, T., Sabarirajan, N., Karthick, S. (2020). Machining parameters optimization of Aluminium Alloy 6063 with reinforcement of $\mathrm{SiC}$ composites. Materials Today: Proceedings. https://doi.org/10.1016/j.matpr.2019.12.085

[5] Muthukumar, K., Sabariraj, R.V., Kumar, S.D., Sathish, T. (2020). Investigation of thermal conductivity and thermal resistance analysis on different combination of natural fiber composites of Banana, Pineapple and Jute. Materials Today: Proceedings, 21: 976-980. https://doi.org/10.1016/j.matpr.2019.09.140

[6] Mehar, A., Ahmed, G.S., Kumar, G.P., Rahman, M.A., Qayum, M.A. (2015). Experimental investigation and FE analysis of CFRP composites. Materials Today: Proceedings, 2(4-5): 2831-2839. https://doi.org/10.1016/j.matpr.2015.07.297

[7] Sathish, T. (2018). BONN Technique: Tribological properties predictor for plasma nitrided 316L stainless steel. Materials Today: Proceedings, 5(6): 14545-14552. https://doi.org/10.1016/j.matpr.2018.03.044

[8] Navaneetha Krishnan, G., Selvam, V., Saravanan, C. (2015). Effect of CNTs-Fe2O3 hybrids on mechanical studies of glass fibre/epoxy nanocomposites. Pharmaceutical Chemistry Journal, 6: 196-201.

[9] Sathish, T. (2018). GAC-ANN technique for prediction of spring back effect in wipe bending process of sheet metal. Materials Today: Proceedings, 5(6): 14448-14457. https://doi.org/10.1016/j.matpr.2018.03.031

[10] Sathish, T., Chandramohan, D., Vijayan, V., Sebastian, P.J. (2019). Investigation on microstructural and mechanical properties of $\mathrm{Cu}$ reinforced with Sic composites prepared by microwave sintering process. Journal of New Materials for Electrochemical Systems, 22(1): 5-9. https://doi.org/10.14447/jnmes.v22i1.a02

[11] Praveen Kumar, R., Navaneethakrishnan, G., Umanath, K. (2018). Experimental analysis of glass fibre - sisal reinforced composite material. Int. J. Mech. Production Engg. Research and Development, 8: 943.

[12] Sathish, T., Saravanan, S., Vijayan, V. (2019). Effect of reinforced aluminium alloy LM30 with pure ceramic particles to evaluate hardness and wear properties. Materials Research Innovations, 24(3): 129-132. https://doi.org/10.1080/14328917.2019.1614321

[13] Parameswaran, P., Rameshbabu, A.M., Krishnan, G.N., Yogeshwaran, R., Ramkumar, R. (2018). Study of the corrosion properties in a hot forged $\mathrm{Cu}-\mathrm{Al}-\mathrm{Ni}$ alloy with added Cr. Journal of the Mechanical Behavior of Materials, 27(3-4): 1. https://doi.org/10.1515/jmbm2018-0016

[14] Praveen Kumar, R., Navaneethakrishnan, G., Umanath, K. (2018). Experimental investigation on mechanical 
properties of hybrid composite material. Int. J. Mech. Production Engg. Research and Development, 8: 1264.

[15] Saravanan, C., Subramanian, K., Anandakrishnan, V., Sathish, S. (2018). Tribological behavior of AA7075TiC composites by powder metallurgy. Industrial Lubrication and Tribology, 70(6): 1066-1071. https://doi.org/10.1108/ILT-10-2017-0312

[16] Sinteza, I., Kompozitov, M. (2018). Synthesis and forming behaviour of AA7075-TiC powder-metallurgy composites. Synthesis, 52(6): 809-812. https://doi.org/10.17222/mit.2017.189

[17] Saravanan, C., Subramanian, K., Krishnan, V.A., Narayanan, R.S. (2015). Effect of particulate reinforced aluminium metal matrix composite-a review. Mechanics and Mechanical Engineering, 19(1): 23-30.

[18] Verma, A., Negi, P., Singh, V.K. (2018). Experimental investigation of chicken feather fiber and crumb rubber reformed epoxy resin hybrid composite: mechanical and microstructural characterization. Journal of the Mechanical Behavior of Materials, 27(3-4): 1. https://doi.org/10.1515/jmbm-2018-0014

[19] Ku, H., Wang, H., Pattarachaiyakoop, N., Trada, M. (2011). A review on the tensile properties of natural fiber reinforced polymer composites. Composites Part B: Engineering, 42(4): https://doi.org/10.1016/j.compositesb.2011.01.010

[20] Ramesh, M., Sudharsan, P. (2018). Experimental investigation of mechanical and morphological properties of flax-glass fiber reinforced hybrid composite using finite element analysis. Silicon, 10(3), 747-757. https://doi.org/10.1007/s12633-016-9526-5

[21] Khatkar, V., Vijayalakshmi, A. S., Manjunath, R. N., Olhan, S., \& Behera, B. K. (2020). Experimental Investigation into the Mechanical Behavior of Textile Composites with Various Fiber Reinforcement Architectures. Mechanics of Composite Materials, 56(3): 367-378. https://doi.org/10.1007/s1 1029-020-09888-0

[22] Parameswaran, P., Vijayan, V., Radhakrishnan, K., \& Antony, A. G. (2019). Evaluation of Mechanical Properties of Banana and Glass-Epoxy Hybrid Composites with Addition of Copper Powder. International Journal of Vehicle Structures \& Systems (IJVSS), 11(3): 320-324. https://doi.org/10.4273/ijvss.11.3.20 